\title{
ERROS DIDÁTICOS E ERROS CONCEITUAIS NO ENSINO DA GEOGRAFIA: RETIFICAÇÕES E MEDIAÇÕES À CONSTRUÇÃO DO CONHECIMENTO
}

\author{
DIDACTIC AND CONCEPTUAL ERRORS IN THE TEACHING \\ OF GEOGRAPHY: RECTIFICATIONS AND MEDIATIONS \\ FOR THE CONSTRUCTION OF KNOWLEDGE
}

ERRORES DIDÁCTICOS Y ERRORES CONCEPTUALES EN LA

ENSEÑANZA DE GEOGRAFÍA: RECTIFICACIONES Y MEDIACIONES

PARA LA CONSTRUCCIÓN DEL CONOCIMIENTO

\author{
Vanilton Camilo de Souza - Universidade Federal de Goiás - Goiânia - Goiás - Brasil \\ souzavanilton@ig.com.br
}

\begin{abstract}
Sônia Maria Vanzella Castellar - Universidade de São Paulo - São Paulo - São Paulo - Brasil smvc@usp.br
\end{abstract}

\begin{abstract}
Resumo
Uma das grandes tarefas postas atualmente é lidar com o Ensino de Geografia, assim como de outras disciplinas. Tal fato implica processos epistemológicos tanto em relação à formação do professor quanto à do aluno. 0 presente artigo analisa o processo de construção do conhecimento no Ensino de Geografia, focando a presença de erros didáticos e erros conceituais no ensino desta disciplina. Ao analisar sobre os erros, argumentaremos a importância da retificação dos mesmos como dimensão importante à mediação didática $\mathrm{e}$ à construção de um conhecimento geográfico no âmbito escolar. Os fundamentos para nossas análises focam na filosofia de Gaston Bachelard, centralmente em relação ao lugar do erro nos processos epistêmicos. Se há erros, há de ter retificação dos mesmos para então superar obstáculos epistemológicos e ascender a um novo conhecimento.
\end{abstract}

Palavras-chave: ensino de geografia, erros didáticos e conceituais, retificação e mediação.

Abstract

Currently, one of the primary tasks is to deal with the Teaching of Geography, as well as of other disciplines. This fact implies epistemological processes relating to both the formation of teachers and students. The present paper analyses the process of knowledge construction in the Teaching of Geography, focusing on the presence of didactic and conceptual errors and in the teaching of this discipline. When analyzing about errors, we will argue the importance of rectifying them as an essential dimension to didactic mediation and the construction of geographical knowledge in the school context. The foundations of our analyzes focus on the philosophy of Gaston Bachelard, centered about the role of error in epistemic processes. If there are errors, there must be a rectification of them to then overcome epistemological obstacles and acquire new knowledge. Keywords: geography teaching, didactic and conceptual errors, rectification and mediation.

\section{Resumen}

Una de las grandes tareas que se propone en la actualidad es hacer frente a la Enseñanza de Geografía, así como de otras asignaturas. Ese hecho envuelve procesos epistemológicos tanto en relación a la formación del 
profesorado como a la formación del alumno. Este artículo analiza el proceso de construcción de conocimiento en la Enseñanza de Geografía, dando énfasis a la presencia de errores didácticos y errores conceptuales en la enseñanza de esa asignatura. Al analizar los errores, argumentaremos a respecto de la importancia de la rectificación de los mismos, como dimensión importante para la mediación didáctica y para la construcción del conocimiento geográfico en el ámbito escolar. Las bases teóricas para nuestro análisis se centran en la filosofía de Gaston Bachelard, centralmente en relación al lugar del error en los procesos epistémicos. Si hay errores, debe haber rectificación de los mismos para, de esa forma, superar obstáculos epistemológicos y ascender a un nuevo conocimiento.

Palabras-clave: enseñanza de geografía, errores didácticos y conceptuales, rectificación y mediación.

\section{Introdução}

Estamos convictos de que a construção do conhecimento está pautada nas ações cognitivas do sujeito e que essas ações são decorrentes de processos complexos do pensamento que permitem a estruturação do raciocínio. Assim, o raciocínio, por sua vez, do nosso ponto de vista, é mais consistente quando o pensamento é motivado pela relação que se estabelece entre o conhecimento científico e as concepções de mundo presentes nas práticas cotidianas do sujeito. Em outras palavras: o desenvolvimento do pensamento terá mais solidez se os conhecimentos tiverem sentido para que o sujeito se interesse pelos fenômenos sociais, naturais, políticos, econômicos e culturais que ocorrem em nossa sociedade e, se possível, para a vida prática. Nessa perspectiva, defendemos que aprender Geografia é fundamental, de um lado, a coerência e a aproximação teórico-metodológica que se estabelece entre a Geografia, a Filosofia e a Educação, centralmente. Por outro lado, há de se considerar os processos psicológicos que permitem ao aluno internalizar os conhecimentos e exercer coerentemente/autonomamente a sua prática social. Ao entendermos que a construção do conhecimento é um processo e que as relações entre o objeto do conhecimento e o sujeito não se dão de forma natural, simples e ou mecânicas há de se considerar como se ensina e que a mediação do professor (no sentido vigostikiano), é o que pode possibilitar o desenvolvimento do pensamento. Também julgamos que as mediações para esse processo não ocorrem naturalmente, mecanicamente. Elas (as mediações) devem ser intencionais, tendo por base os saberes prévios dos alunos e o conhecimento da Geografia, sendo, dessa forma, mediações propiciadas pelo professor, o que denominamos de mediação didática (D’Ávila, 2008). 
É nessa perspectiva que refletiremos sobre o lugar do erro na construção do conhecimento sobre o Ensino da Geografia, considerando-o como dimensão importante à ação mediadora e à aproximação entre os saberes prévios e o conhecimento de Geografia que defendemos. Tomaremos nesse artigo a concepção de erro na perspectiva de Gaston Bachelard $^{1}$ e, a partir desse fundamento, nos propomos a refletir sobre os erros no ensino da disciplina.

Os estudos sobre Gaston Bachelard no Ensino da Geografia, especificamente os relativos à retificação do erro como dimensão capaz de superar os obstáculos epistemológicos presentes na formação do professor de Geografia, têm ocorrido em momentos distintos.

Há muitos anos, a professora Sônia Castellar tem estudado sobre a importância desse filósofo na sua prática como pesquisadora, professora e orientadora na pós-graduação. Uma das ideias importantes de Bachelard está relacionada com a superação dos obstáculos e do erro. Trata-se de sair da contemplação do mesmo para buscar o outro, para dialetizar a experiência, o que remete à necessidade de diversificar o pensamento e superar as certezas, reorganizando o pensamento e os saberes. Nesse sentido, o autor afirma que:

a tarefa difícil é colocar a cultura científica em estado de mobilização permanente, substituir o saber fechado e estático por um conhecimento aberto e dinâmico, dialetizar todas as variáveis experimentais, oferecer enfim à razão razões para evoluir (Bachelard,1996, p. 24).

A compreensão de uma palavra ou termo requer vários significados, que podem ser factuais ou epistemológicos, mostrando que, a partir de um conceito, pode-se obter outro ou analisar sua relação com outro. Nesse esquema, o mundo empírico, vivido pelo aluno, pode proporcionar noções sobre o mundo teórico. A vivência do aluno e a ação docente - por meio de problematizações, pesquisas, aulas expositivas, trabalhos de campo - contribuirão para que aquele consiga estruturar e construir conceitos científicos no campo do mundo teórico. (Castellar, 2010).

Outro momento ocorreu nos diálogos estabelecidos pelo professor Vanilton Camilo de Souza com um grupo de Didática das Ciências Sociais

\footnotetext{
'Existem trabalhos no Ensino de Geografia referenciados por Gaston Bachelard "noturno", dos devaneios. Nesse trabalho, tomamos como referência o Bachelard Epistêmico, "diurno".
} 
e Experimentais da Universidade de Sevilla, por ocasião do doutorado sanduíche desenvolvido pelo mesmo nessa universidade. Nesse diálogo, tomamos Bachelard, especificamente a categoria erro, como objeto central das discussões. Por meio desse grupo, acessamos as produções do francês Pierre Astolfi, quem primeiro sistematizou as contribuições do erro na perspectiva bachelardiana para o ensino. No Brasil, esses fundamentos didáticos são bastante incorporados no ensino de ciências.

Por sua vez, as discussões sobre Bacherlard no Ensino de Geografia obtiveram novas sistematizações por ocasião do pós-doutoramento na Faculdade de Educação da Universidade de São Paulo (FEUSP), em que os autores deste texto dialogaram sobre as potencialidades dessa categoria no processo de formação do professor de Geografia ${ }^{2}$. Ou seja, objetivamos, centralmente, analisar sobre os erros didáticos e epistemológicos que se manifestam no processo de formação do professor de Geografia e sobre suas possíveis superações como forma de mediar o conhecimento dos futuros professores.

Diante do exposto, indagamos: qual a relação que estabelecemos entre as teorias educacionais, as teorias geográficas e os fundamentos da filosofia bachelardiana no processo de construção de uma metodologia de ensino coerente com o que se pensa e com o que se ensina? Qual a conexão possível entre tais fundamentos e as realidades socioculturais/ socioespaciais da Geografia Escolar? As conexões mobilizam o pensamento? Que obstáculos teóricos, conceituais e didáticos induzem ao erro no Ensino de Geografia? Em que medida a retificação do erro é dimensão didática capaz de mediar o conhecimento em Geografia?

Na tentativa de refletir sobre essas questões, o trabalho apresentará a seguinte estrutura: na primeira parte, explicitaremos elementos centrais dos fundamentos sobre construção do conhecimento, sobre o papel do erro nesse processo (e na filosofia bachelardiana), para, em seguida, apontarmos quais erros didáticos e conceituais consideramos frequentes no Ensino de Geografia e em que medida esses erros podem potencializar a construção do conhecimento deste assunto na Geografia Escolar.

\footnotetext{
${ }^{2}$ Nesse período de pós-doutoramento em que os autores (pós-doutorando e supervisor) se debruçaram sobre pesquisas desenvolvidas por ambos nos últimos anos, inclusive das pesquisas em curso durante o estágio pós-doutoral, centraram suas as análises ao que chamamos de erros didáticos e erros conceituais no Ensino da Geografia. Foi a partir dessas reflexões e sob fundamentos de Bachelard $(1968,1996,2004)$ e Astolfi $(1988,1994,2003)$, centralmente, que desenvolvemos esse texto.
} 


\section{0 erro na construção do conhecimento da Geografia Escolar}

Para se pensar sobre construção de conhecimentos, é necessária uma sólida ideia dos processos epistêmicos pelos quais esse conhecimento é construído, uma boa compreensão das teorias da Ciência Geográfica e uma sólida compreensão dos saberes provenientes de outras áreas (Educação, Sociologia, História etc.). Ao tomar por base o conjunto dos conhecimentos veiculados no meio social, percebemos que o processo de construção do conhecimento é mais complexo do que parece à primeira vista. Tal complexidade advém das diversas percepções que orientam as pessoas a olhar para o mundo, falar sobre ele e agir nele. $O$ fato é que, do nosso ponto de vista e diante da complexidade de visões de mundo, os saberes das ciências são considerados os que possibilitariam uma melhor articulação dessa diversidade de saberes na formação dos indivíduos numa dimensão crítica.

Um dos principais problemas no campo da Filosofia tem sido a discussão sobre a teoria do conhecimento, sobretudo, desde o surgimento da ciência moderna. É recorrente a ideia de que a racionalidade é o fundamento essencial do conhecimento. A razão constitui uma das formas mais utilizadas para a explicação do mundo e para a produção de conceitos e teorias. Na atualidade, são vários os legados da ciência para a compreensão dos fenômenos encontrados na literatura referentes aos campos da Filosofia, das Ciências Sociais e da Educação. Nesses legados reside o fato de que o conhecimento científico pressupõe processo de superação epistêmica de saberes e conceitos considerados descontextualizados para os dias atuais e que podem ser recontextualizados em outro momento histórico. Na história da ciência, a exemplo, a lei de termodinâmica ainda é válida para além da Física Moderna. No caso da Geografia o conceito de cidade ganha outras interpretações culturais e sociais, mas continua tendo a mesma base conceitual desde o seu surgimento.

Sobre esse aspecto, tomamos como referencial as contribuições de Gaston Bachelard, considerado um importante filósofo contemporâneo a criticar a imagem tradicional da ciência de orientação empirista indutivista. São muitas as obras que expõem a sua epistemologia e é, sobretudo, na obra Filosofia do Não que o pensador anuncia a necessidade de fundar uma nova filosofia da ciência, mais adequada ao pensamento científico em contínua evolução. Para Bachelard (1978), não se pode pensar 
numa filosofia finalista e absoluta na produção científica ${ }^{3}$. Outra obra fundamental para a compreensão da filosofia bachelardiana é $A$ formação do espírito científico (Bachelard, 1996). Nessa obra, encontram-se as orientações básicas para se construir um novo pensamento científico. Tais orientações decorrem da ideia de lidar com os obstáculos epistemológicos no sentido de superá-los, para, então, ascender ao espírito científico. Destacam-se, também, as contribuições do livro Ensaios sobre o conhecimento aproximado (Bachelard, 2004), no qual Bachelard amplia sua filosofia sobre a produção do conhecimento. Nessa obra, uma das grandes contribuições trata-se da necessidade de retificar o erro como processo de conhecer a realidade. O erro é, para Bachelard, o ponto de partida para ascender ao espírito científico, opondo-se ao processo de busca da verdade, como propõe a filosofia empirista indutivista. A questão do papel do erro na construção do conhecimento do professor é importante referência para uma didática da Geografia, sendo dimensão que nos propomos nessa parte do texto.

As obras de Bachelard referidas não tratam de educação ou da educação escolar, no entanto, elas nos servem de referência quando tratamos do ensino e dos processos de aprendizagem, especificamente sobre o ensino

\footnotetext{
${ }^{3}$ Cabe uma nota para que possamos fazer uma articulação entre o pensamento científico e a compreensão da realidade, justificando ainda mais a necessidade da superação dos obstáculos epistemológicos para compreender o mundo geograficamente: o papel essencial dos adventos científicos e tecnológicos no avanço político e econômico das nações. Essa questão se torna ainda mais evidente quando se destaca um dos principais componentes que sustentaram o desenvolvimento dessas sociedades: as máquinas térmicas.
}

As máquinas movidas a vapor foram aparatos tecnológicos que alteraram expressivamente as estruturas industriais e, por consequência, a organização das sociedades. Estas têm seu funcionamento regido por diversos princípios científicos associados ao campo da termodinâmica que, em conjunto com as leis da mecânica e, posteriormente, com as leis do eletromagnetismo permitiram desenvolver inúmeros novos processos de geração de energia.

Nos dias atuais, a mera observação de uma panela de pressão preenchida com líquido, tampada e levada ao fogo permite fazer a associação que outrora foi algo de grande engenhosidade: calor e movimento são grandezas que estão diretamente relacionadas. Podemos, então, notar facilmente que as máquinas térmicas transformam calor em movimento, ou seja, mais precisamente, realizam trabalho a partir de trocas de calor. Essa ideia básica já era conhecida no século III a.C. por Heron de Alexandria, que desenvolveu uma máquina a vapor denominada eolípila (do grego, aeolipile), que "produzia ventos" a partir do aquecimento de uma esfera oca preenchida por água.

0 uso da expansão controlada do vapor de água como fonte de energia mecânica nos permite por em pauta diversas discussões muito interessantes sobre as relações entre uso de determinadas fontes de energia e a organização das sociedades.

0 primeiro aspecto a se destacar é decorrente da resposta à seguinte pergunta: por que foi na Inglaterra do final do século XVIII que o motor a vapor ganhou impulso efetivo, vindo a tornar-se o mecanismo dominante de toda a produção e transporte? (Castellar; Picazzio, 2014). 
de ciências (Garcia Perez; Rivero, 1995; Astolfi, 2003, 1994 e 1988). Com efeito, considera-se que diversos aspectos do pensamento desse filósofo possam orientar os processos de aprendizagem e de construção do conhecimento em diversos campos disciplinares, especificamente no âmbito da educação superior. É uma contribuição que se acredita compor um sistema teórico e conceitual necessário para a formação acadêmica e profissional desejável, da qual pode participar, inclusive, o professor de Geografia.

A perspectiva bachelardiana oferece elementos importantes para a construção do conhecimento sobre a Geografia Escolar e que, tanto as categorias de obstáculos epistemológicos quanto a de positividade do erro são dimensões teóricas constitutivas de um processo epistêmico capaz de desenvolver um pensamento dialético podendo resultar em pensamentos geográficos de base crítica. O comentário na nota de rodapé dá essa dimensão de algo importante como o advento científico nos permite entender conceitos geográficos como produção, indústria e transportes, ou seja, a dinâmica do território. Essa articulação entre os conhecimentos da Física e da Geografia estimulam uma leitura de mundo que contribui positivamente para a superação dos obstáculos e do erro.

Para Bachelard, os obstáculos epistemológicos decorrem de um conjunto de fatores vinculados à maneira pela qual as pessoas percebem a realidade e que impede os indivíduos de ascenderem ao conhecimento científico. Tais obstáculos decorrem de elementos internos e externos ao ato de pensar. Dessa forma, para vencer os obstáculos epistemológicos, deve-se estar em constante processo de vigilância epistêmica, sob pena de ocorrer o enrijecimento do conhecimento e, dessa forma, não se obter o progresso epistemológico.

Ao analisar o processo de construção do conhecimento geográfico na formação inicial de professores, Souza (2009) apontou alguns aspectos que Bachelard considera constitutivos de tais obstáculos. Um dos principais elementos que constituem obstáculos epistemológicos na formação do professor de Geografia seria o que Bachelard definiu como observação primeira da realidade. A forte influência do ensino tradicional da disciplina, a tradição da pesquisa de caráter empirista da ciência geográfica, a importância dada à observação como atividade-fim, são considerados obstáculos na medida em que a realidade é concebida pela empiricidade do fenômeno e por considerar os aspectos óbvios da percepção. Segundo o autor: 
a experiência primeira ou, para ser mais exato, a observação primeira é sempre um obstáculo inicial para a cultura científica. De fato, essa observação primeira apresenta-se repleta de imagens; é pitoresca, concreta, natural, fácil. Basta descrevê-la para se ficar encantado. Parece que a compreendemos (Bachelard, 1996, p. 25).

A observação primeira da realidade é consideração importante na construção de um conhecimento sobre a Geografia. No entanto, ela não deve ter como objetivo ser uma atividade que tem um fim em si mesma. Nas palavras de Bachelard, o objeto nunca é aquilo que se mostra, por isso a necessidade de trazer à tona todas as explicações do fenômeno depois de observá-lo com cuidado. A depender do ponto de vista, a observação primeira pode ser um erro e obstaculizar o conhecimento. Em outro ponto de vista, no entanto, a observação é fundamental para interpretar fatos e fenômenos geográficos. Vale dizer que o pensamento epistêmico desse filósofo promove perspectivas didáticas para se superar tais obstáculos.

A retificação do erro, por sua vez, é dimensão capaz de promover a construção do conhecimento em Geografia. A retificação do erro e a mediação são, respectivamente, categorias apropriadas a esse processo que se vinculam à ação do pensamento do indivíduo inserido num universo social e cultural rico em informações e técnicas capazes de promover uma ação epistêmica. Tal ação poderá promover relações qualitativas com a realidade. No caso da episteme geográfica, trata-se de realidade social / espacial / temporal / cultural, nas quais o sujeito está inserido, tendo em vista o processo cognitivo sobre elas empreendido. É possível, assim, apresentar suportes didáticos para a efetivação de um processo de construção do conhecimento mais eficaz para o ensino da Geografia.

A partir dos erros presentes na prática pedagógica cotidiana (nos textos geográficos, nos enunciados elaborados pelo professor, nas respostas dos alunos) é possível uma mediação didática mais eficaz em que se utilizem os conceitos da disciplina e o conhecimento profissional do professor de Geografia para retificar os erros dos alunos. Segundo Bachelard, “o problema do erro nos parece mais importante que o problema da verdade; ou melhor, só encontramos uma solução possível para o problema da verdade quando afastamos erros cada vez mais refinados”. (Bachelard, 2004, p. 246).

O autor, portanto está se referindo à positividade do erro como elemento motor do conhecimento e como alternativa necessária para o 
desenvolvimento cognitivo individual. Assim, é plausível à epistemologia bachelardiana a existência de concepções alternativas, reveladoras das "impurezas e valores" adquiridos pelo conhecimento sensível, na interação dos sujeitos com outros sujeitos e do sujeito com o mundo que o cerca. A objetividade de uma ideia será mais clara e mais distinta na medida em que ela aparecer sobre um fundo de erros mais profundos e mais diversos. É preciso errar para atingir um fim. Não há verdades primeiras, só erros primeiros. A primeira e mais rica função do sujeito é a de se enganar. Quanto mais complexo for seu erro, mais rica será sua experiência. A experiência é a lembrança dos erros retificados. Nessa perspectiva, "o erro é uma fase da dialética que precisa ser transposta. Ele suscita uma investigação mais precisa, é o motor do conhecimento" (Bachelard, 2004, p. 251).

Consideramos dessa forma que o erro tem sua positividade na medida em que ele é retificado. É dizer: se não somos atentos aos erros presentes em nossa prática social/profissional para então retificá-los, nos aproximamos de profissionais/intelectuais com características muito próximas à arrogância. Tomado sob essa perspectiva, o erro torna-se obstáculo para a construção do conhecimento. Em outra perspectiva, o erro pode nos acender ao espírito científico. Astolfi (2003, p. 36) aponta que “[...] el obstáculos es um 'tejido de errores construídos', tenaces y solidários, que se resiste, por tanto, a la refutación”. São raras as experiências que tomam a avaliação como mecanismo capaz de identificar os erros para, a partir deles, pensar as ações didáticas. Os obstáculos são, antes de tudo, aspectos positivos que trazem grandes benefícios ao pensamento, ao exercício mental, enfim, ao processo de construção do conhecimento para qualquer nível educativo. Numa metáfora proposta pelo autor, o erro e os obstáculos proporcionam uma forma de pensar com a mente sentada em um sofá (Astolfi, 2003).

O erro tem sido bastante estudado no campo educacional, pois essa categoria implica uma perspectiva didática interessante no processo de construção do conhecimento. Muitos ainda coadunam com a dimensão negativa à didática que usa o erro para punir e classificar; discriminar os que aprendem dos que não aprendem; diferenciar os que merecem boas notas daqueles que não darão conta de passar de ano. Opostamente à essa perspectiva, há uma positividade do erro no processo de ensino, sendo que, a partir dele, podemos tomar as reais possibilidades de o aluno 
construir seus próprios conceitos e, com isso, ser sujeito autônomo em sua aprendizagem. Na prática pedagógica, o erro pode significar uma possibilidade concreta de evoluir o pensamento.

\section{Erros didáticos no ensino da Geografia}

O que denominaremos de erros didáticos no ensino da Geografia não significa dizer que os mesmos sejam desprovidos de erros conceituais próprios do campo da Didática da Geografia. Entendemos aqui esse termo como sendo aquele que se situa no contexto dos encaminhamentos didáticos na sala de aula pelo professor e que as ocorrências se definem, em boa parte, por inconsistências teóricas relacionadas ao processo de ensino e aprendizagem na disciplina, podendo haver, portanto, relação com os erros conceituais da Geografia. Consideramos quatro erros didáticos muito presentes na Geografia Escolar: o primeiro diz respeito ao ensino centrado na transmissão dos conteúdos de Geografia, o segundo diz respeito à concepção de planejamento de ensino, o terceiro é relativo à centralidade dos conteúdos para ensinar Geografia e o quarto, o trabalho de campo.

Em relação ao primeiro erro didático, Souza (2009) analisou o papel da transmissão de conteúdo compreendendo-o como componente de um modelo didático muito próprio do ensino tradicional e muito presente na formação do professor de Geografia. O modelo se sustenta na ideia de que o conhecimento da Geografia de base acadêmica, centralmente, é o verdadeiro e, portanto, é papel da escola referenciar-se por ele. $\mathrm{O}$ processo de construção desse conhecimento é decorrente essencialmente da transmissão. A transmissão de conteúdos constitui-se como erro didático na nossa concepção pelo seguinte fato: se um professor tivesse a convicção de que o processo de construção de conhecimento que ele defende se sustenta sobre esse modelo e que a transmissão de conteúdos é o procedimento mais adequado a essa concepção, ele não se caracterizaria como um erro didático. O que ocorre é que há uma forte tendência de, nas práticas discursivas, os professores defenderem outro modelo didático, o crítico, e na composição dos procedimentos didáticos para ensinar Geografia, a transmissão de conteúdo, centrado no professor, acaba por se tornar o encaminhamento central. A exemplo, o construtivismo, nas suas diversas formulações, compõe orientação pedagógica muito comum nos discursos dos professores. O mesmo é recorrente na formação inicial 
do professor de Geografia. É comum os nossos alunos explicitarem em seus trabalhos acadêmicos concepções pedagógicas criticando os modelos tradicionais de ensino. Essa prática reforça a ideia que a boa aula é a transmitida. Quando analisamos seus planos de ensino e suas práticas durante o estágio nas escolas, a transmissão de conteúdos se caracteriza como essência de suas práticas, ao mesmo tempo em que se sentem frustrados com os resultados por considerarem que os alunos não aprenderam a Geografia. A essência desse procedimento reforça uma prática que não leva em conta o que o aluno já sabe (conhecimento prévio), no contexto das intenções pedagógicas se caracteriza como erro didático. Que procedimentos de ensino superam a transmissão de conteúdos? O que os procedimentos didáticos têm a ver com o que defendemos enquanto processo epistêmico alternativo?

Souza e Silva (2015, p. 169) apresentam elementos capazes de retificar a ideia de ensino centrado na transmissão de conteúdos, com destaque: a capacidade de problematizar a unidade/temática identificando os obstáculos da aprendizagem; buscar informações/conteúdos tendo como fundamento básico a interpretação, a comparação, a análise dentre outros processos cognitivos; delinear a importância desses conteúdos para a vida cotidiana dos alunos; sintetizar, escrever, produzir narrativas.

A transmissão de conteúdos como erro didático na Geografia Escolar se articula, por vezes, com o segundo erro didático: a concepção de planejamento de ensino. O que é um planejamento de ensino? Para que se planeja? Qual é o papel do planejamento no processo de construção do conhecimento que se defende? É comum a ideia de que o planejamento é uma peça burocrática na escola; que o que se planeja não se efetiva na prática; que o planejamento do professor é cópia de outros planos já existentes; etc.

O plano de ensino é, sob o nosso ponto de vista, etapa essencial a um processo de conhecimento geográfico que defendemos. No momento de se pensar os objetivos da matéria é, também, quando se define o que se considera central para o ensino da Geografia, desde sobre o que é Geografia, que Geografia se defende e que Geografia eu quero que meus alunos aprendam até os conteúdos mais específicos. O plano de ensino favorece a superação do erro didático quando se explicita com objetividade a Geografia que se efetivará na sala de aula bem como as estratégias de ensino. 
Pelo plano de ensino é possível, também, o professor demonstrar sua autonomia, seus conhecimentos e sua capacidade de se defrontar com as diversas propostas curriculares que lhe chegam à escola. É no ato de planejar, tendo os objetivos como referência, que o professor selecionará os conteúdos da Geografia que melhor atendam a cada um dos objetivos, de forma que os mesmos possam ter significado para os alunos. Articulados às demais dimensões do plano de ensino, os procedimentos não poderão ser incompatíveis com o que se pretende ensinar. Há de se ter uma posição articulada para implantação dos objetivos, dos conteúdos e dos métodos de ensino (Libânio, 2010). O ato de planejar é importante para que se possam superar possíveis erros didáticos que muitas vezes são recorrentes nas ações cotidianas. O planejamento do curso e da aula pode contribuir para a manutenção do erro didático, pois revela a concepção que se tem sobre o significado de planejar.

O terceiro erro didático versa sobre os conteúdos como dimensão central para ensinar Geografia e é muito presente nas práticas de ensino principalmente no planejamento e nas aulas da disciplina. É comum, como já mencionamos, iniciar o planejamento pela seleção dos conteúdos e o livro didático disponível é a principal referência para selecioná-los. Da mesma forma, é comum nas aulas de Geografia, a exposição ser o procedimento didático central e os conteúdos selecionados gravitarem esse tipo de aula. Na falta da exposição, a leitura de texto do livro didático e ou a cópia dos conteúdos reproduzidos no quadro compõem a estrutura central das aulas de Geografia. Essa centralidade nos conteúdos decorre, com intensidade, por acreditar que se não os apresentar e não o explicar bem e com antecedência, os alunos não conseguiram desenvolver as atividades/exercícios, portanto, não compreenderão a matéria.

Consideramos que os conteúdos são dimensão importante na atividade de ensino. Ele, no entanto, tem a função de atender aos objetivos do que se quer ensinar. Que conteúdos selecionar nessa perspectiva? Todos os conteúdos disponíveis em um dado livro didático, por exemplo, atendem às pretensões postas nos objetivos? É nos objetivos que o professor define que pensamento geográfico quer que o aluno desenvolva. Pensar o ensino sob esse ponto de vista é estabelecer uma posição de autonomia por parte do professor e os conteúdos é que serão selecionados como a dimensão do conhecimento geográfico que, naquele momento, atende ao objetivo pretendido. 
Por fim, o quarto erro didático é o trabalho de campo, por residir no fato de que esse procedimento, em muitas situações de ensino, se caracteriza como atividade cujo objetivo se remete às dimensões tradicionais da Geografia, em que o trabalho de campo não problematiza as concepções prévias dos alunos, não explicita a complexidade espacial, ou ainda, é usado recorrentemente para mostrar as formas espaciais. $\mathrm{O}$ trabalho de campo como erro didático, revela, por vezes, uma herança do papel que esse procedimento tem para a tradição geográfica, ainda fortemente marcada pela tradição da pesquisa de caráter empirista da ciência e da importância dada à observação como atividade-fim.

Para além dessas perspectivas, o trabalho de campo pode contribuir como procedimento didático para estimular as mais complexas leituras e reflexões sobre as dinâmicas espaciais. Uma atividade na qual, para além das aparências observadas no espaço, possa-se compreender a sua funcionalidade, a sua historicidade, as relações de poder na produção desse espaço, etc. O trabalho de campo pode ser um momento de superação do erro didático e dos obstáculos epistemológicos quando entende que é um procedimento que pode ser investigativo, ou seja, utilizado como método para se entender um fenômeno, um lugar, um objeto, e a partir dele observar, descrever, analisar, interpretar o que está sendo estudado. O trabalho de campo supera obstáculos quando leva em consideração as perguntas e hipóteses dos alunos, seus conhecimentos prévios e a cultura do lugar.

Um aspecto importante e que precisa ser incorporado na ação didática é ter o trabalho de campo como rico procedimento para ensinar por conceitos geográficos e cartográficos. A exemplo, tomamos as contribuições de Milton Santos de quem apreendemos que o espaço deve ser visto na sua aparência e na sua essência. A essência é tomada pela manifestação de aspectos que não são visíveis. Seria, por exemplo, a adoção da noção de totalidade na compreensão do espaço. A especificidade desse processo de análise do espaço para um encaminhamento didático sobre o trabalho de campo decorreria, a partir do uso das categorias forma, função, estrutura e processo (Santos, 1985).

A concepção que apresentamos sobre a importância do planejamento e plano de ensino revela a maneira como entendemos o processo de ensino e aprendizagem. O trabalho de campo, por exemplo, é um procedimento que pode ser significativo se for inserido nas atividades de aula como 
um processo investigativo, com registro das hipóteses, dos cenários para análise e das interpretações dos elementos estruturantes da Geografia.

\section{Erros conceituais no ensino de Geografia}

Os erros conceituais são decorrentes da internalização de um dado conceito da Geografia nas estruturas mentais do professor (ou do aluno, quando for o caso), sendo essa concepção internalizada a que frequentemente orienta as práticas de ensino. Os conceitos são frequentemente adquiridos pela cultura experiencial, portanto, é na sala de aula que ocorrerá a superação, ou seja, o tratamento que é dado aos conteúdos precisa levar em conta o que se sabe sobre ele, mas também a representação do que se tem do conceito estudado. Isso implica aproximar o conceito da realidade, estabelecendo uma relação a partir de perguntas que estimulem os alunos a ampliar o repertório sobre as leituras, as representações, as vivências que eles têm do mundo. $\mathrm{O}$ erro conceitual é, dessa forma, uma manifestação que faz parte do processo de ensino e aprendizagem. Essa proposta pedagógica, que começa pelas situações do cotidiano, das práticas da vida, estimula o interesse, e o sentido do conhecimento científico faz parte das metodologias ativas que passo a passo supera o pensamento comum, agregando nele outros elementos da cultura e da ciência. As atividades didáticas em suas diferentes versões, nesta perspectiva teórica cognitiva ou sociocognitiva, nos ajudam nas mudanças conceituais.

s estudos sobre os erros conceituais no campo educacional são mais evidentes nas pesquisas da Didática das Ciências dentre os quais podemos destacar Astolfi (2003) e (Lopes 1993) e na Didática das Ciências Sociais, com destaque a García Pérez e Riveiro (1995). Essas pesquisas são referências para se pensar os erros conceituais no ensino de Geografia pelo fato de que a base dos erros nessas pesquisas diz respeito à epistemologia da construção do conhecimento. Ou seja, se a posição epistemológica que se defende é, na prática, contraditória, gera erro conceitual. Os erros conceituais são, centralmente, erros de fundo epistêmico. Modificar uma concepção/posição epistemológica é sempre mais difícil.

Quando se procuram as condições psicológicas dos progressos da ciência, em breve se chega à convicção de que é em termos de obstáculos que se deve pôr o problema do conhecimento 
científico. E não se trata de considerar obstáculos externos como a complexidade e a fugacidade dos fenômenos, nem tão-pouco de incriminar a fraqueza dos sentidos e do espírito humano: é no próprio ato de conhecer, intimamente, que aparecem, por uma espécie de necessidade funcional, lentidões e perturbações. É aqui que residem causas de estagnação e mesmo de regressão, é aqui que iremos descobrir causas de inércia a que chamaremos obstáculos epistemológicos. O conhecimento do real é uma luz que sempre projeta algures umas sombras. Nunca é imediato e pleno. As revelações do real são sempre recorrentes. O real nunca é $<<$ aquilo que se poderia crer $>>$, mas é sempre aquilo que se deveria ter pensado. O pensamento empírico é claro, fora de tempo, quando o aparelho das razões já foi afinado. Ao desdizer um passado de erros, encontramos a verdade num autêntico arrependimento intelectual. Com efeito, nós conhecemos contra um conhecimento anterior, destruindo conhecimentos mal feitos, ultrapassando aquilo que, no próprio espírito, constitui um obstáculo à espiritualização. (Bachelard, 2006, p. 165)

Afirmamos, dessa forma, que parte dos erros conceituais da Geografia na formação e na prática do professor são erros centrados na perspectiva epistêmica da ciência que a concebe como aquela que busca a verdade e que emana o conhecimento como uma verdade absoluta, inalterada, sem erros ou com possibilidades de reformulações conceituais, que não é subjetiva e que a verdade é a ação da objetividade da realidade pelo investigador.

Os erros conceituais, nesse sentido, podem ter ligações a fontes distintas: erros decorrentes das experiências cotidianas e erros decorrentes da própria ciência na formação do professor, na prática docente e ou nos textos didáticos. Esses erros se constituem, sob o nosso ponto de vista, em grandes obstáculos à construção de uma Geografia Escolar que defendemos. Como já dissemos anteriormente, os erros didáticos podem ter um fundo teórico e epistemológico da disciplina nas suas manifestações. Da mesma forma, os erros conceituais podem orientar encaminhamentos didáticos com a Geografia que defendemos.

Dos conceitos que estruturam a Geografia Escolar, a concepção de paisagem pode ser a primeira a ser entendida, centralmente, como um conjunto de objetos naturais e ou estáticos; outro erro conceitual ocorre com o de lugar, cuja concepção está referendada na localização de objetos no espaço e ou adensamentos desses objetos; o terceiro trata-se da relação cidade-campo tendo por base a concepção de que uma é oposição à outra 
e que a cidade domina o campo; e por sua vez, o quarto erro diz respeito à cartografia presente no ensino de Geografia, neste caso, em relação aos conceitos.

Ao nos referirmos aos conceitos, destacamos o de paisagem por ser um dos mais trabalhados em sala de aula desde os anos iniciais. A experiência da vida cotidiana tem em si a contemplação da paisagem, um olhar para o que vivencia um cenário e seus vários elementos físicos sociais. A paisagem é o que se vê, mas ela é também dinâmica e se transforma. Por isso, em relação à superação do erro conceitual, neste caso seria tratá-la como uma dimensão estática do espaço observado e apenas descritiva. Esses são erros conceituais para ensinar paisagem na perspectiva que defendemos, tendo como referência a definição de Cavalcanti (2008, p. 51,52).

O conceito de paisagem, ainda que não seja específico da Geografia, é clássico na constituição dessa ciência, estando tradicionalmente ligado a aspectos de uma área de descrição possível; creio mesmo que hoje se possa destacar o fato de ser a paisagem o domínio do visível - a expressão visível de um espaço -, o domínio do aparente, de tudo que na nossa visão alcança; o domínio do que é vivido diretamente com nosso corpo, com nossos sentidos - visão audição, olfato, paladar; ou seja, trata-se da dimensão das formas que expressam o movimento da sociedade. A observação e compreensão dessas formas servem para dar caminhos de análises do espaço. Nesse sentido tem lugar tanto os aspectos objetivos captados na paisagem, quanto os aspectos subjetivos dos sujeitos que dão significados e sentidos aos elementos dessa paisagem. As paisagens são assim expressões técnicas, funcionais e estéticas da sociedade. São também dinâmicas e históricas, já que se trata de expressões de movimentos da sociedade. Pode-se dizer, assim, que, pela observação dos objetos da paisagem - observação que é subjetiva e seletiva -, percebem-se as ações sociais, as contradições sociais, as testemunhas de ações passadas, de distintos tempos.

Desse excerto, vale destacarmos expressões significativas para justificarmos a concepção de paisagem como erro conceitual no ensino da Geografia: subjetivação, movimento social das formas da paisagem, dinâmicas históricas, significação e função. Essas expressões que se contrapõem à perspectiva racionalista que concebe a paisagem, principalmente, como dimensão de um espaço estático, absoluto, racional, pouco relacional e não histórico. 
Outro conceito caro à Geografia é o de lugar, que está presente em várias atividades didáticas. As concepções mais recorrentes desse conceito são: lugar como sinônimo do local, de onde é possível identificar, localizar os objetos no espaço; lugar de adensamentos de determinados objetos; o lugar da vivência como espaço das experiências cotidianas; e como qualquer lugar da superfície terrestre. Pensar as localidades, os adensamentos e as experiências cotidianas é importante para se pensar o referido conceito geográfico, porém, numa perspectiva dialética, essa abordagem não é suficiente. Para Cavalcanti (1998, p. 91) “a compreensão de que o lugar só pode ser entendido como expressão da totalidade, inacabada, aberta e em movimento, leva à necessidade de ampliar o entendimento do vivido para o concebido", do espaço vivido à experiência e o espaço concebido às representações inclusive as cartográficas. Para ampliar ainda mais o conceito de lugar, podemos associá-lo ao conceito de escala geográfica. Sendo este um atributo do raciocínio espacial, além da generalização é uma dimensão importante para se pensar o lugar na perspectiva das diferentes escalas, como afirma Santos (1994):

o ponto de encontro de lógicas que trabalham em diferentes escalas, reveladoras de níveis diversos, e às vezes contrastantes, na busca da eficácia e do lucro, no uso de tecnologias do capital e do trabalho. O lugar é o ponto de encontro de interesses longínquos e próximos, locais e globais (p. 18-19).

Apesar de defenderem uma Geografia Crítica, nos diálogos que temos estabelecido com os professores e licenciandos de Geografia, foi comum encontrarmos encaminhamentos práticos com concepções de lugar como a localização. É essa incoerência teórica e metodológica que acaba se tornando obstáculos epistemológicos para os alunos, devido à fragilidade conceitual dos professores, o que interfere no plano de ensino, inviabilizando uma prática de aula significativa, tratando o conceito de lugar, por exemplo, no senso comum. Do nosso ponto de vista, o empreendimento de diversas escalas geográficas para se pensar o conceito de lugar é dimensão central ampliando a concepção relacionada às práticas cotidianas, retificando o erro conceitual da Geografia.

No que diz respeito à relação cidade-campo como erro conceitual no ensino de Geografia, tomamos o fato de que é muito presente a ideia de que a cidade é a dimensão espacial que domina o campo e este, por sua vez, pouco interfere na espacialidade do urbano. Essa concepção ainda 
marca fortemente o Ensino de Geografia, que coloca esses espaços em contraposição, com características próprias e isoladas. Apesar de ainda se conceber essa relação cidade campo, sob o nosso ponto de vista, esses espaços possuem relações de interdependência, de complementaridade, de relações integradas, de uma totalidade una, bem mais forte do que se parece à primeira vista. Apesar de serem espaços de paisagens distintas, há uma forte interseção econômica, cultural, social, política, simbólica, que dinamizam a relação cidade-campo.

Esse conceito está presente em muitos conteúdos da Geografia Escolar e aparece nos discursos dos professores ou em atividades de classe como espaços dicotômicos. Esse é um erro conceitual comum quando se contrapõem esses espaços como aparecem nos trabalhos dos alunos sobre o tema. Os estudantes expressam, por um lado, (boa parte das vezes por figuras) o campo como espacialidade do atraso, espaço bucólico, de meio ambiente saudável, natureza natural e, por outro lado, a cidade como lugar da modernidade, de tecnologia avançada, de gente inteligente, etc. O professor, por sua vez, pouco problematiza tais percepções do aluno sobre a relação cidade-campo. Para retificar esse conceito, é importante uma abordagem que conceba tais espacialidades numa perspectiva do conceito de totalidade e ou de espaços integrados.

O erro conceitual também está presente ao se ensinar cartografia para os alunos. Neste caso, os conceitos que estruturam a cartografia para se ensinar Geografia são: legenda, ponto, área e linha, escala, visão vertical e oblíqua, imagem bidimensional e tridimensional, orientação espacial. Esses conceitos são relevantes não apenas para ler um mapa temático, por exemplo, como também estimular o pensamento espacial por meio de conceitos de distância, direção, proximidade, sítio ou topografia. Os mecanismos de pensar e compreender espacialmente os lugares são atributos importantes da Geografia, portanto, quando não são trabalhados em sala de aula, acabam desestimulando os alunos a lerem e elaborar mapas, a se perceber espacialmente, a compreender a lógica das relações entre os lugares. Esses problemas podem ser obstáculos para se entender Geografia e, consequentemente, o mundo.

Nesse contexto, a superação dos obstáculos epistemológicos é fazer com que os alunos tenham um sistema de referência elevado para que possam utilizar de diferentes maneiras no seu cotidiano. Quando os professores não trabalham em sala de aula e nem colocam em seus 
planos de ensino as bases para o ensino da cartografia escolar, acabam contribuindo para que os alunos fiquem sem condições de levantar suas hipóteses sobre a localização, as distâncias, entre outras conexões espaciais, como afirma Germshel e Gersmehl (2013) o processo de ligação entre "o onde" - fatos de localização - com "os quais" - fatos de condições e conexões - é mais complexo e indireto do que muitas pessoas suspeitam. O ensino de cartografia na escola é uma base importante para o desenvolvimento sócio cognitivo e espacial dos alunos.

\section{Ensinar por conceitos: potencialidade à superação ${ }^{4}$ dos erros}

Entendemos que poderemos adotar diversas abordagens para encaminhar o ato de ensinar a Geografia e que poderiam ser consideradas propostas de ensino capazes de superar os erros e, com isso, ir concretizando o processo de retificação dos mesmos. A retificação de erros de fundo epistemológico, segundo Bachelard, aponta que o ponto de partida para o desenvolvimento de um conhecimento que se defende deve se iniciar por um problema. O problema, nessa perspectiva, é a resposta à pergunta. Em outras palavras: "[...] precisamente o sentido do problema que dá a marca do verdadeiro espírito científico.” (Bachelard, 2006, p. 166). Para que ocorram superações de erros no Ensino de Geografia, não é producente dizer apenas que o professor está errado, que os conceitos de Geografia que ele carrega não são atualizados. Há de se criar situações que problematizem tais concepções, situações que motivem o sujeito a conhecer outras perspectivas condizentes ao que se intenciona ensinar, sabendo que erros de natureza epistêmica não são resolvidos rapidamente.

A metodologia de ensinar por conceitos (Souza, 2011; Souza; Silva, 2015; Cavalcanti, 1998; 2005) pode se constituir numa abordagem potencializadora à retificação do erro no Ensino da Geografia. Compreendemos que o ensinar e o aprender, como organizações sociocognitivas, "são partes integrantes da prática social historicamente constituída” (Castellar, 2010, p. 42). Ensinar por conceito; nessa perspectiva, é fundamental o papel do professor criando situações didáticas capazes de dinamizar a relação entre o sujeito e o objeto. Para tal dinamização, aproximação dos conhecimentos da Geografia com os saberes dos alunos, o professor utilizaria um conjunto de instrumentos 
que permitissem aos alunos um movimento constante no seu processo de ensino e de aprendizagem: a capacidade de problematizar, de sistematizar e sintetizar (Cavalcanti, 2014).

Como se expôs, ao pensar no desenvolvimento de aulas significativas e investigativas para os alunos, defendemos a concepção que a formação de conceitos se torna uma metodologia fecunda, capaz de estabelecer um suporte teórico e metodológico para ensinar a Geografia. Compreendemos ainda que, para um bom desenvolvimento de se ensinar por conceito, a identificação de erros e sua retificação no ensino de Geografia são de fundamental importância para que o aluno queira de fato se apropriar de conhecimentos que possam ser úteis no seu cotidiano e como formação cidadã.

\section{Considerações Finais}

Consideramos que a construção de um conhecimento científico não é uma tarefa simples devido aos problemas conceituais geográficos e pedagógicos. A compreensão das bases teórico-metodológicas pode ser um facilitador, pois contribuiria para a superação de um ensino tradicional, com foco no professor; contribuiria também para que o professor superasse a didática tradicional que, por vezes, são incompatíveis com a ideia de conhecimento que defendemos. Tal tarefa não é simples, em decorrência de que o processo de construção de conhecimento da Geografia Escolar que defendemos é um processo epistêmico e, como já argumentamos, as mudanças do pensamento de base epistêmica são muito complexas. Não é simples, pois, avançar epistemologicamente. Significa reconhecer a presença de erros em nossa prática social cotidiana e o erro é ferozmente punido em nossa sociedade, é severamente criticado nas nossas práticas de ensino na escola. Não é simples, pois, retificar o erro e mediar situações de aprendizagem significativa é superar os obstáculos epistemológicos. Significa ter boa base de conhecimentos teóricos sobre Geografia, Educação, Filosofia e Psicologia, ou seja, uma sólida formação inicial.

É munidos de uma sólida base teórico e metodológica que seremos capazes de superar os erros didáticos e conceituais no ensino da Geografia, como já dissemos anteriormente. É fundamental que superemos a noção de conhecimento como algo pronto e a substituamos pela concepção de que o conhecimento é relativo e processual; que se supere a noção de tempo 
de formação imediatista e quantitativa pela noção do tempo cognoscitivo do aluno; que se supere a noção de aprendizagem como produto por uma noção de aprendizagem como processo.

Procuramos demonstrar que é na complexidade dos fundamentos teóricos e metodológicos no Ensino da Geografia que nos sentimos motivados ao ato de conhecer e, no nosso caso, de identificar erros didáticos e conceituais para então retificá-los, para, então, vermos uma Geografia na escola valorizada pelos seus alunos, uma Geografia que tenha sentido para os alunos verem, compreenderem e agirem no espaço em diversas escalas. Por fim, entender que identificar erros em nossas práticas sociais cotidianas e, especificamente, em nossas práticas de ensino não é um ato de vergonha e sim uma possibilidade de desenvolver o "nosso espírito científico".

\section{Referências}

ASTOLFI, J. P. El “error”, un médio para enseñar. Sevilla: Diada, 2003.

. El trabajo didáctico de los obstáculos en el corazón de los aprendizajes científicos. Enseñanza de las ciencias. 1994, 12 (2), 206-216.

. El aprendizaje de conceptos científicos: aspectos epistemológicos, cognitivos y linguísticos. Enseñanza de las ciencias. 1988, 6 (2), 147-155.

BACHELARD, G. O novo espírito científico. Rio de Janeiro: Tempo Brasileiro, 1968. . A filosofia do não. São Paulo: Abril Cultural, 1978. . A formação do espírito científico. Trad. Estela dos Santos Abreu. Rio de Janeiro: contraponto, 1996.

.Ensaio sobre conhecimento aproximado. Rio de Janeiro: Contraponto, 2004 .

CASTELLAR, S. Educação geográfica: formação e cidadania. In: MORAIS, E. M. B. de; MORAES, L. B. de. Formação de professores: conteúdos e metodologias no processo de ensino e aprendizagem de Geografia. Goiânia: NEPEG, VIEIRA. 2010.

CASTELlAR, S. M. V; PICAZZIO, E. Energia, Ciência Aplicada e Tecnologia. Material Didático elaborado para o curso de graduação em Licenciatura em Ciências, modalidade EaD, Universidade de São Paulo, 2014.

CAVALCANTI, L. S. Geografia, Escola e construção do conhecimento. Campinas: Papirus, 1998. 
- Cotidiano, mediação pedagógica e formação de conceitos: uma contribuição de Vygotsky ao Ensino de Geografia. Caderno Cedes. Campinas, vol. 25, n. 66, p. 185-207, maio/ago. 2005.

. Geografia Escolar e a Cidade ensaios sobre o ensino de geografia para a vida urbana cotidiana. Campinas: Papirus, 2008.

. A metrópole em foco no Ensino de Geografia: o que/para que/para quem ensinar? In: PAULA, F. L. de A; CAVALCANTI, L. S. SOUZA, V. C. (Orgs.). Ensino de Geografia e Metrópole. Goiânia: América, 2014.

D’ÁVILA, C. Decifra-me ou te devorarei: o que pode o professor frente ao livro didático? Salvador: EDUNEB/EDUFBA, 2008.

GARCÍA PÉREZ, F. F. Un modelo didáctico alternativo para transformar la educación: el modelo de investigación en la escuela. Scripta Nova. Revista Electrónica de Geografía y Ciencias Sociales. Universidad de Barcelona, n. 64, 15 de mayo de 2000.

GARCÍA PEREZ, F. F.; RIVERO, A. Dificultades y obstáculos em la construcción del conocimiento escolar em una hipótesis de progresión de lo simple a lo complejo. Reflexiones desde el ámbito del medio urbano. Investigación en la Escuela. No 27, Sevilla, 1995.

GERSMEHL, P. J.; GERSMEHL, C. A. Spatial thinking by young children: Neurologic evidence for early development and "educability". Journal of Geography, v.106, n.5, p.181-191, 2007. Disponível em <http://dx.doi. org/10.1080/00221340701809108> Acesso em 05 set. 2013.

LIBÂNEO, J. C. Didática. São Paulo: Cortez, 2010.

LOPES, A. R. C. Contribuições de Gaston Bachelard ao ensino de ciências. Enseñanza de las Ciencias, 1993, 11 (3), 324-330.

SANTOS, M. Espaço e método. São Paulo: Nobel, 1985.

SANTOS, M. Técnica, espaço, tempo: globalização e meio técnicocientífico informacional. São Paulo: Hucitec, 1994.

SOUZA, V. C. Fundamentos Teóricos, Epistemológicos e Didáticos no Ensino da Geografia: bases para a formação do pensamento espacial crítico. Revista brasileira de Educação em Geografia, v. 1, p. 47-67, 2011.

. O Processo de Construção do Conhecimento Geográfico na Formação Inicial de Professores. 2009. 210f. Tese (Doutorado em Ciências Humanas). Universidade Federal de Goiás, Goiânia, 2009.

SOUZA, V. C.; SILVA, T. A. Ensinar Geografia pela construção de conceitos. In: Xosé Carlos Macía Arce; Francisco Rodrígues Lestegás; Francisco Xosé Armas Quintá. (Org.). Ensinar Geografia, realidades e propostas no Brasil e Galiza. 01 ed. Santiago de Compostela: Andavira, 2015, v. 1, p. 01-229. 
Vanilton Camilo de Souza - Possui Graduação em Geografia pela Pontifícia Universidade Católica de Goiás. Possui mestrado em Educação pela Universidade Federal de Minas Gerais. É Doutor em Geografia pela Universidade Federal de Goiás. Possui Pós-Doutorado pela Universidade de São Paulo. Atualmente é professor Adjunto da Universidade Federal de Goiás

Sônia Maria Vanzella Castellar - Possui graduação em Geografia pela Universidade de São Paulo, mestrado em Didática e Doutorado em Geografia pela mesma Universidade. Atualmente é professora de Metodologia do Ensino de Geografia da Faculdade de Educação da Universidade de São Paulo.

Contribuição de cada autor no desenvolvimento do artigo

Todos os autores contribuíram efetivamente na produção desse artigo e, conjuntamente, elaboraram a estrutura do texto. O primeiro autor redigiu uma parte do manuscrito relativo aos fundamentos teórico-conceitual, centralmente ao conceito de erros conceituais na Geografia. O segundo autor efetivou uma revisão crítica à primeira versão do texto e redigiu o conceito de erros didáticos no ensino da Geografia 
